\title{
Mindfulness Meditation: A Primer for Rheumatologists
}

\author{
Laura A. Young, M.D., Ph.D.[Assistant Professor of Medicine] \\ Division of Endocrinology Department of Internal Medicine University of North Carolina School of \\ Medicine
}

\section{Keywords}

fibromyalgia; rheumatoid arthritis; osteoarthritis; mindfulness meditation; Mindfulness Based

Stress Reduction (MBSR); stress

\section{Introduction}

Meditation, with its origins rooted in ancient religious and spiritual practices dating back over 2,500 years ago, has only in the past several decades begun to capture the attention of mainstream Western researchers and healthcare providers who are gradually beginning to value this mind-body practice as a tool to foster improved physiological and psychological health [1]. In the current medical environment, it is not uncommon for patients to report the use of mind-body therapies as an adjunct to Western medical treatment[2]. Over the past decade there has been increasing interest in meditation as a mind-body approach, in mindfulness meditation, given its potential to alleviate emotional distress and promote improved well-being in a variety of populations[3-5]. The overall purpose of this review is to provide the practicing rheumatologist with an overview of mindfulness and how it can be applied to Western medical treatment plans to enhance both the medical and psychological care of patients.

\section{What is Mindfulness?}

The word mindfulness is derived from the Pali word sati, meaning "to remember", with secondary meanings of "attention" and "awareness". Remembering refers to reconnecting to the immediate moment of experience, not the recollection of a past event. A contemporary definition of mindfulness offered by Kabat-Zinn, states that mindfulness is the awareness that emerges through, "paying attention on purpose, in the present moment, and nonjudgmentally, to the unfolding of experience moment to moment"[6]. Similar descriptions are offered by other leaders in the field including: "mindfulness is the nonjudgmental observation of the ongoing stream of internal and external stimuli as they arise"; and "a receptive attention to and awareness of present events and experience" $[7,8]$. Notably, two concepts pervade these descriptions of mindfulness: 1) holding one's attention in the present moment; and 2) maintaining an attitude of acceptance, openness, and non-judgment [9]. The

(C) 2010 Elsevier Inc. All rights reserved.

Corresponding author: Laura A. Young, MD, PhD Assistant Professor of Medicine Division of Endocrinology University of North Carolina 8023 Burnett Womack Building Campus Box \# 7170 UNC-CH Chapel Hill, NC 27599-7170 Phone: (919) 966-3465 office phone Fax: (919) 966-6025 Laura_Young@ med.unc.edu.

Publisher's Disclaimer: This is a PDF file of an unedited manuscript that has been accepted for publication. As a service to our customers we are providing this early version of the manuscript. The manuscript will undergo copyediting, typesetting, and review of the resulting proof before it is published in its final citable form. Please note that during the production process errors may be discovered which could affect the content, and all legal disclaimers that apply to the journal pertain. 
validity of this two component model has been debated; however, it still remains a useful, widely accepted definition[10,11].

Mindfulness meditation (process) is a mental technique which is used to strengthen the capacity to establish and sustain mindful awareness (outcome) [12]. The practice of mindful meditation cultivates attentional focus and stability by directing the mind to remain connected to the present moment experience. Attention is usually sustained by concentrating on the breath [6]. Participants are instructed to follow the flowing cycle of breathing with their full attention. Depending upon the exercise, the focus of attention can vary and may include sensations in the body during rest or movement, a sound, or a visual focus like a candle flame or an image. Although the object of focus varies, in all instances the goal of the practice is to train attention to remain fully engaged with the experience and remain in the present moment. While this may seem simple; after attempting to keep attention focused for only a few moments, it is natural for novices to relate difficulty maintaining focus on the present moment. Without training attention drifts and becomes lost in memories of the past and thoughts of the future. With practice over time, remaining in the present becomes easier and is more likely to occur spontaneously. Meditation is simply a tool to assist in the acquisition of an awareness which is broad, balanced, present-focused, and behaviorally neutral.

\section{Health Benefits Linked to Mindfulness Practice}

A relatively wide collection of studies, of varying quality, in healthy subjects have linked mindfulness training to improvements in stress, anxiety, and depressed mood [13-16]. Mindfulness is also effective at decreasing stress and promoting positive mood states in patients with a variety of chronic health conditions [17-28]. Studies examining the effects of mindfulness training on traditional Western medicine outcomes, including morbidity and mortality, are beginning to emerge [28]. Data from the field of psychiatry and mental health shows that mindfulness interventions can be efficacious in the treatment of mood disorders $[5,7,29]$. Furthermore, accumulating data supports the notion that mindfulness meditation may ameliorate physiological changes that accompany chronic mental and emotional stress, including improved cortisol secretion profiles and beneficial anatomic changes in the brain $[30,31]$. While these early findings are encouraging, clearly additional work examining psychological and physiological changes that occur during and following mindfulness meditation training to further examine the health benefits are necessary.

\section{Proposed Mechanisms of Action}

Given the significant salutary effects of mindfulness training, the question remains, "what mechanisms are mediating these outcomes?" [5,7,31]. The mechanisms through which mindfulness decreases stress and increases well-being are not well understood; however a variety of proposed mechanisms of action abound in the literature. We will briefly review several of the more prominent theories. One popular hypothesis is that the cultivation of mindfulness facilitates a fundamental shift in perspective, termed reperceiving [11]. Similar to decentering, reperceiving refers to observing one's thoughts and feelings as temporary, emotion-neutral events occurring in the mind which do not require judgment. Shapiro theorized that reperceiving leads to greater clarity, objectivity, and equanimity, and facilitates improved self-regulation, values clarification, cognitive and emotional flexibility. Empiric testing of this theory however suggests that reperceiving and mindfulness are in fact overlapping constructs and there is little support that reperceiving alone mediates improvements in psychological outcome variables [32]. Others speculate that it is the development of mindful awareness that mediates improved psychological outcomes [33]. In a group of novices, there was a positive relationship between the time practicing meditation 
and 1) the tendency to be mindful in daily life; 2) psychological improvements. Increased mindfulness in turn mediated the relationship between time spent meditating and reductions in stress and improvements in psychological functioning [34]. Additional work supporting this concept showed that long-term meditation practice is associated with being able to describe one's internal experiences with words and to be nonjudgemental and non-reactive toward them [35]. Furthermore, these key constructs of mindfulness were found to mediate the relationship between meditation experience (measured in months) and well-being in experienced meditators. These findings support the notion that mindfulness is cultivated through meditation and may mediate the relationship between meditation practice and improved mental health.

Experimentally, changes in the ability to direct and manage attention have been demonstrated after only five days of mindfulness meditation training as well as after longer periods of training [36,37], however what is the therapeutic value of maintaining a presentfocused attention that is non-judgmental and non-reactive? Self-focused attention, in the form of rumination, is linked to a variety of psychological maladies and poor outcomes. Rumination is the mental propensity to repetitively think about situations, thoughts, feelings or emotions which are typically of a negative nature. It has been theorized that the selffocused nature of the rumination is not harmful; rather it is how one processes these thoughts that predicts maladaptive outcomes. Sustaining a mindful self-focus that encourages a non-judgmental, non-reactive awareness of the present moment, even in subjects prone to rumination, promotes a mode of self-thought processing that is more adaptive [38,39]. Additional benefits of self-focused attention have been theorized including increased mental flexibility, improved self-regulation, decreased emotional reactivity, and reduced avoidance [24,40-42]. For a more in depth consideration of these issues, readers are directed to Baer's thoughtful review [43].

\section{Common Methods Used to Teach Mindfulness}

In this section we will briefly review the most common mindfulness approaches utilized by patients. The intent is to enable the practicing rheumatologist to make more informed recommendations to patients interested in incorporating mindfulness into their treatment plans. The completely secular nature these approaches accommodates a wide audience. These interventions follow in the footsteps of earlier psychological approaches, including behavioral therapy and cognitive behavioral therapy (CBT). In stark contrast to CBT, where the emphasis is on the use of cognitive restructuring of beliefs that mediate negative affect, the so called "third wave" therapies promote the creation of a constructive relationship with disturbing emotions, which ultimately promotes acceptance[44].

\section{Mindfulness Based Stress Reduction (MBSR)}

Likely the most well-known and popular program designed to train participants in mindfulness, is the Mindfulness-Based Stress Reduction (MBSR) program, developed in the 1970's by Jon Kabat-Zinn at the University of Massachusetts [24]. Initially developed as a behavioral intervention for patients with chronic pain and stress-related conditions, MBSR has expanded globally and can now be found in a variety of health care and community settings and in over 400 hospital and medical school settings in the United States [21]. MBSR is a standardized program conducted as an 8-week class with weekly sessions typically lasting 2.5 to 3 hours. During the training participants practice: 1 ) sitting meditation using the breath as an anchor; 2) contemplative walking; 3) mindful movement through the use of gentle Hatha type yoga postures; and 4) the body scan in which participants practice attention control by systematically focusing on the sensations in various parts of the body. Near the end of the 8-week training program application of mindful awareness to daily activities, often referred to as "informal mindfulness practice," is 
encouraged. Mindfulness activities are practiced both in class and as homework. Audio recordings are provided to support home practice. Participants are expected to complete approximately 45 minutes of formal mindfulness practice at least 6 days per week during the eight week period. During an all day retreat near the end of the training, participants remain in silence and have the opportunity to practice their newly acquired mindfulness skills during a sustained and uninterrupted period of time. An essential component of the weekly classes includes discussion about the experiences that occur during the practice of mindfulness both in and out of the classroom. The impact of teacher experience, frequency of weekly session attendance, duration of home practice and frequency of home practice likely affects the degree of symptomatic improvement reported by participants, but results have been mixed [18,19,45-49]. Patients can be referred to the Center for Mindfulness in Medicine, Healthcare, and Society at the University of Massachusetts for a listing of teachers who have completed standardized MBSR training

(http://www.umassmed.edu/cfm/stress/index.aspx).

\section{Mindfulness Based Cognitive Therapy (MBCT)}

Largely based on the concepts of mindfulness derived from MBSR, the focus of MBCT is on the treatment of depression rather than stress [50]. Specifically designed for use in the prevention of depression relapse, its theoretical foundation rests upon research showing that those individuals most vulnerable to depression relapse are those who have mood-related reactivation of negative thinking patterns and inappropriate responses to negative thoughts and emotions [51-53]. A combination of mindfulness training and cognitive therapy are utilized to cultivate a de-centered approach to internal experience. Unlike traditional CBT exercises that attempt to change thoughts, in MBCT the focus is on acceptance rather than change. Since this is a relatively new intervention there is currently no network of qualified providers. Creators of the intervention recommend using their book, The Mindful Way Through Depression, and/or working with a teacher or therapist who incorporates MBSR or other mindfulness practices into their work for those interested in this approach [54].

\section{Dialectical Behavior Therapy (DBT)}

Originally developed through insight gained while working with patients who had suicidal ideation and borderline personality disorder, this treatment program is a modified CBT program, drawing from principals in behavioral science, dialectical philosophy and Zen meditation practice [55]. Therapists and clients work to balance change with acceptance. Traditional cognitive behavioral therapy helps the participant change inappropriate behaviors, thoughts and emotions, while mindfulness training helps to facilitate acceptance and change. Participants are asked to make a one year commitment to the therapy. There are several components to DBT therapy including individual psychotherapy, group skills training, and telephone consultations between sessions. Readers are referred to the DBT training manual for a more in depth review [40].

\section{Clinical Applications of Mindfulness Specific to the Practicing Rheumatologist}

While there is a growing body of evidence supporting the use of mindfulness training as an adjunct to conventional therapy for a variety of medical and psychological conditions, studies specifically examining this intervention in patients with rheumatologic conditions are limited. The discussion below highlights several clinical concerns that that are frequently encountered by the practicing rheumatologist in which the mindfulness training may be beneficial. 


\section{Chronic Pain}

Collectively, rheumatologic diseases have been classified to be the most prominent cause of chronic pain in the developed world [56,57]. Chronic pain is often associated with a multitude of challenges not only for the patient, but also the cadre of family, friends, and healthcare providers caring for them. Uncontrolled chronic pain can lead to poorer quality of life, disability, and psychosocial problems in patients with rheumatologic conditions[58]. While most health care providers are aware of the role the mind-body connection has in partially mediating chronic pain symptoms, many feel under-prepared and/or unqualified to make recommendations for therapeutic interventions intended to target this important, symptom modifying axis $[59,60]$. Despite the fact that a wide range of mind-body therapies have been shown to be effective for the treatment of chronic pain and the inclusion of these interventions into comprehensive treatment plans has been recommended by consensus panels, only $20 \%$ of patients with chronic pain report the use of such adjunctive therapies $[61,62]$.

Cognitive behavioral therapy (CBT) is a widely utilized and accepted mind-body approach which utilizes cognitive restructuring to modify maladaptive thoughts and behaviors related to pain; however the overall reported effects sizes for CBT are generally small in patients with chronic pain $[63,64]$. Eliminating maladaptive thoughts may not be a realistic strategy in patients with rheumatologic conditions who suffer from chronic pain since most face continual daily reminders of their chronic medical problems. A more realistic approach may be the promotion of acceptance. Mindfulness-based approaches to pain management encourage participants to alter their relationships and reflexive, behavioral responses to these maladaptive thoughts through non-judgmental acceptance. Pain acceptance has been described as "a willingness to experience continuing pain without needing to reduce, avoid, or otherwise change it" [65]. Experienced mindfulness practitioners demonstrate reduced anticipation and negative appraisal of pain under experimental conditions [66]. Higher degrees of mindfulness in patients with chronic pain are related to lower self-reported pain, emotional distress, disability, and utilization of pain medication [67]. Lower degrees of mindfulness are related to greater distorted thinking about pain, specifically pain catastrophizing, characterized by rumination about pain, feelings of hopelessness, and exaggeration of pain-related symptoms [68].

Training in mindfulness, particularly through the use of MBSR, has been shown to be effective for the treatment of chronic pain originating from a variety of causes, although not all studies have shown positive results related to pain reduction [21-26]. A recent uncontrolled, observational study suggests that of participants enrolled in a community based MBSR training program who reported chronic pain, exhibit improvements in pain scores following completion of the course [49]. Participants with chronic neck/back pain and arthritis were most likely to have significant improvements in pain following the MBSR training, while those with fibromyalgia and chronic headache did not have significant improvement in self-reported pain, suggesting a potential role in certain patients with rheumatologic disease.

Some of the highest quality evaluations of mindfulness interventions in chronic pain have been in patients with rheumatoid arthritis, osteoarthritis, and fibromyalgia. After 8 weeks of training, self reported pain significantly improved in 144 participants with rheumatoid arthritis regardless of intervention (CBT vs. mindfulness training vs. disease education), although greater effects were seen with CBT and education compared to mindfulness training [69]. Mindfulness training did not positively impact subjects' perceived control over their pain, while CBT and education did show beneficial effects. The relative value of the treatments in patients with RA varied based upon depression history. Those with a history of 
2 or more episodes of depression who completed mindfulness training were more likely to show improvements in pain coping self-efficacy, pain catastrophizing, and physician assessed joint tenderness and joint swelling. The data supporting the use of mindfulness in patients with pain due to osteoarthritis is less compelling. In two different heterogeneous groups of older adults with chronic low back pain, in which a large proportion of the participants attributed the cause of their pain to osteoarthritis, MBSR subjects report of pain was not significantly different from those in the wait-list control or educational control conditions [70,71]. Chronic pain self-efficacy and disability scores improved in both the mindfulness and educational control groups [71]. In the first randomized controlled trail of a mindfulness based intervention for women with fibromyalgia, significant improvements in pain were noted for those in the mindfulness group compared to the waitlist control condition [72]. Similar findings were noted in 58 women with fibromyalgia participating in a quasi-randomized trial. Self-reported pain scores, pain perception, and the ability to cope with pain improved following an 8-week MBSR training compared to the support control group immediately following the intervention. Improvements were maintained over a 3 year follow-up time period [73]. In contrast, Astin showed similar improvements in pain in subjects with fibromyalgia completing a mindfulness based movement class compared to those in an educational control group [74]. While no conclusive recommendations can be made regarding the use of mindfulness interventions as an adjunctive means to control pain in patients with rheumatologic conditions, these initial findings suggest mindfulness training does not cause harm.

\section{Mental Health}

The benefits of mindfulness training particularly on depression and anxiety have been repeatedly shown in a variety of populations, including in those with chronic medical conditions [5,75-78]. As discussed above, a more mindful awareness might buffer against the harmful influence of perceived stress on psychological well-being, particularly in people who are susceptible to poor psychological functioning. Similar to other populations, improvements in mood have been shown to occur following mindfulness training in patients with rheumatologic conditions. In patients with rheumatoid arthritis, immediately following MBSR training, there were no notable improvements in psychological distress or depressive affect; however, 4 months following the intervention, improvements in psychological distress, but not depression, were noted [46]. In a second study of patients with rheumatoid arthritis, positive affect improved for both those receiving CBT and mindfulness, but the greatest improvements in both negative and positive affect were seen in those with a history of 2 or more episodes of depression, suggesting that those with recurrent depression were most responsive to the mindfulness intervention [79]. Modest improvements in psychological distress have been shown following completion of mindfulness training in patients with fibromyalgia compared to controls [72]. In a group 91 women with fibromyalgia, Sephton showed specific improvements in depression in those who had mindfulness training compared to controls [80]. Furthermore, mindfulness training in women with fibromyalgia has been shown to improve patients' sense of optimism and control over their life, which was related to lower depressive symptoms [81]. Mindfulness, combined with a movement intervention was shown to be as efficacious as an educational control group at improving symptoms of depression in subjects with fibromyalgia [74]. Observational data evaluating changes in depression and anxiety before and after MBSR training suggest that patients with fibromyalgia had small non-significant changes in psychological distress, while patients with arthritis had the largest improvements in psychological distress when compared with patients with a other types of chronic pain [49]. Based upon the data, a significant amount of work still needs to be done to evaluate the impact of mindfulness training on mental health in patients with rheumatologic conditions. Given the high rates of clinically significant depression in patients with rheumatologic 
disease, MBCT is a particularly appealing mindfulness approach for the rheumatologist given MBCT's proven track record for depression relapse prevention. MBCT has yet to be formally evaluated in a cohort with a specific rheumatologic disease. One word of caution to practitioners who may want to suggest mindfulness training as an adjunctive approach to a multidisciplinary care plan is that mindfulness interventions may not be appropriate for people who are actively suffering from acute clinical depression. It has been theorized that intensity of negative thoughts, poor concentration and restlessness that often accompany an episode of acute depression might make meaningful participation in mindfulness exercises difficult and uncomfortable. Developing the necessary attentional control skills may be difficult during a major depressive episode, although this long held belief has recently been challenged $[82,83]$.

\section{Immune function}

Accumulating data suggests training in mindfulness meditation may also support improved physiological functioning. While the exact mechanisms remain unknown, it is hypothesized that mindfulness meditation may exert its favorable effects through a variety of pathways including decreased sympathetic activation and improved neuro-endocrine function, two pathways intimately coupled to immune function [84]. In a landmark study, Davison demonstrated that training in mindfulness meditation enhanced antibody production following the influenza vaccination in healthy adults [47]. Extending this work into conditions where immune dysfunction plays an important role, including cancer and HIV infection, has also yielded promising results. In patients with breast and prostate cancer, a shift away from a pro-inflammatory response, to a more anti-inflammatory response, following MBSR participation has been observed [17,18]. This shift away from a proinflammatory state was maintained at the 1 year follow-up time point in this cohort of breast and prostate cancer subjects as evidenced by a continued decrease in Th1 cytokine production [85]. In HIV positive individuals, notable increases in NK cell activity from baseline were noted following MBSR training [86]. In women with early stage breast cancer not undergoing chemotherapy, those who underwent MBSR training displayed a restoration of natural killer cell activity and improvement in cytokine profiles, while those in the control group continued to show immune function abnormalities [87]. The authors speculate that this favorable shift in immune function may be related to lower cortisol secretion in the MBSR group compared to the non-MBSR group. The relationship between improved psychological well-being and improved immune function is less clear, with some studies showing a positive relationship between the two and others showing no association $[17,86,88]$. While these findings are interesting, they are also preliminary, and require confirmation in larger populations. To date, little work has been done on the impact of mindfulness training in patients with rheumatoid arthritis or other rheumatologic conditions, and thus far, mindfulness training has not been shown to have a beneficial effect.

Mindfulness training has not been shown to impact disease activity assessed using the Disease Activity Score (DAS) in 28 joints, which includes a measure of the erythrocyte sedimentation rate, or IL-6 concentrations [46,79].

\section{Conclusion}

Although historically mindfulness meditation is ancient, as described in this review, research in the field is in its early stages though, rapidly expanding in both quality and quantity. This is may be, in part, a response to a controversial AHRQ review that called into question the efficacy of meditation for improving health which cited the rigor of the current studies of meditation as generally poor [89]. None-the-less, it is clear that for many, mindfulness training can have powerful psychological and possibly physiological effects. Many questions remain unanswered and further investigation is warranted. Studies of mindfulness 
do demonstrate that training leads to improved quality of life, including in patients with rheumatologic disease. Taking into consideration that decreased quality of life is common among people with chronic disease and given the generally benign nature of this behavioral intervention, it is perhaps surprising that it is not recommended more often by health care providers in all fields. The clinical importance of improved quality of life as a predictor of morbidity and mortality is debated, but it is difficult to not argue that part of our role as clinicians should be to encourage patients to optimally enjoy life despite chronic medical conditions. We are quickly learning through the power of biomedical research what other cultures have recognized for thousands of years: mindfulness meditation is a powerful tool that can foster improved coping and growth. There is a great deal more that we need to learn, but it seems certain that mindfulness-based interventions have a future in both Western medicine and society.

\section{Acknowledgments}

This work was supported by Grant No. 5K23AT004946-02 from the National Institutes of Health.

\section{References}

1. Ludwig DS, Kabat-Zinn J. Mindfulness in medicine. JAMA 2008;300(11):1350-2. [PubMed: 18799450]

2. Barnes PM, Bloom B, Nahin RL. Complementary and alternative medicine use among adults and children: United States, 2007. Natl Health Stat Report 2008;(12):1-23. (12). [PubMed: 19361005]

3. Reibel DK, Greeson JM, Brainard GC, et al. Mindfulness-based stress reduction and health-related quality of life in a heterogeneous patient population. Gen Hosp Psychiatry 2001;23(4):183-92. [PubMed: 11543844]

4. Chiesa A, Serretti A. Mindfulness-based stress reduction for stress management in healthy people: a review and meta-analysis. J Altern Complement Med 2009;15(5):593-600. [PubMed: 19432513]

5. Grossman P, Niemann L, Schmidt S, et al. Mindfulness-based stress reduction and health benefits. A meta-analysis. J Psychosom Res 2004;57(1):35-43. [PubMed: 15256293]

6. Kabat-Zinn, J. Full Catastrophe Living: Using the Wisdom of Your Body and Mind to Face Stress, Pain, and Illness. 15th Anniversary Ed. Delta Trade Paperback/Bantam Dell; New York, NY US: 2005.

7. Baer RA. Mindfulness training as a clinical intervention: A conceptual and empirical review. Clinical Psychology: Science and Practice 2003;10(2):125-43.

8. Brown KW, Ryan RM. The benefits of being present: mindfulness and its role in psychological well-being. J Pers Soc Psychol 2003;84(4):822-48. [PubMed: 12703651]

9. Bishop SR, Lau M, Shapiro S, et al. Mindfulness: A proposed operational definition. Clinical Psychology: Science and Practice 2004;11(3):230-41.

10. Hayes, SC.; Strosahl, KD.; Wilson, KG. Acceptance and Commitment Therapy: An Experiential Approach to Behavior Change. Guilford Press; New York, NY US: 1999.

11. Shapiro SL, Carlson LE, Astin JA, et al. Mechanisms of mindfulness. J Clin Psychol 2006;62(3): 373-86. [PubMed: 16385481]

12. Shapiro, SL.; Carlson, LE. The Art and Science of Mindfulness: Integrating Mindfulness into Psychology and the Helping Professions. American Psychological Association; Washington, DC US: 2009.

13. Astin JA. Stress reduction through mindfulness meditation: Effects on psychological symptomatology, sense of control, and spiritual experiences. Psychother Psychosom 1997;66(2): 97-106. [PubMed: 9097338]

14. Jain S, Shapiro SL, Swanick S, et al. A Randomized Controlled Trial of Mindfulness Meditation Versus Relaxation Training: Effects on Distress, Positive States of Mind, Rumination, and Distraction. Annals of Behavioral Medicine 2007;33(1):11-21. [PubMed: 17291166] 
15. Klatt MD, Buckworth J, Malarkey WB. Effects of low-dose mindfulness-based stress reduction (MBSR-ld) on working adults. Health Education \& Behavior 2009;36(3):601-14. [PubMed: 18469160]

16. Shapiro SL, Schwartz GE, Bonner G. Effects of mindfulness-based stress reduction on medical and premedical students. J Behav Med 1998;21(6):581-99. [PubMed: 9891256]

17. Carlson LE, Speca M, Patel KD, et al. Mindfulness-based stress reduction in relation to quality of life, mood, symptoms of stress, and immune parameters in breast and prostate cancer outpatients. Psychosom Med 2003;65(4):571-81. [PubMed: 12883107]

18. Carlson LE, Speca M, Patel KD, et al. Mindfulness-based stress reduction in relation to quality of life, mood, symptoms of stress and levels of cortisol, dehydroepiandrosterone sulfate (DHEAS) and melatonin in breast and prostate cancer outpatients. Psychoneuroendocrinology 2004;29(4): 448-74. [PubMed: 14749092]

19. Shapiro SL, Bootzin RR, Figueredo AJ, et al. The efficacy of mindfulness-based stress reduction in the treatment of sleep disturbance in women with breast cancer: an exploratory study. $\mathrm{J}$ Psychosom Res 2003;54(1):85-91. [PubMed: 12505559]

20. Ledesma D, Kumano H. Mindfulness-based stress reduction and cancer: A meta-analysis. Psychooncology 2009;18(6):571-9. [PubMed: 19023879]

21. Kabat-Zinn J, Lipworth L, Burney R. The clinical use of mindfulness meditation for the selfregulation of chronic pain. J Behav Med 1985;8(2):163-90. [PubMed: 3897551]

22. Plews-Ogan M, Owens JE, Goodman M, et al. A pilot study evaluating mindfulness-based stress reduction and massage for the management of chronic pain. J Gen Intern Med 2005;20(12):11368. [PubMed: 16423104]

23. Teixeira ME. Meditation as an intervention for chronic pain: an integrative review. Holist Nurs Pract 2008;22(4):225-34. [PubMed: 18607236]

24. Kabat-Zinn J. An outpatient program in behavioral medicine for chronic pain patients based on the practice of mindfulness meditation: theoretical considerations and preliminary results. Gen Hosp Psychiatry 1982;4(1):33-47. [PubMed: 7042457]

25. Gregg JA, Callaghan GM, Hayes SC, et al. Improving diabetes self-management through acceptance, mindfulness, and values: a randomized controlled trial. J Consult Clin Psychol 2007;75(2):336-43. [PubMed: 17469891]

26. Rosenzweig S, Reibel DK, Greeson JM, et al. Mindfulness-based stress reduction is associated with improved glycemic control in type 2 diabetes mellitus: a pilot study. Altern Ther Health Med 2007;13(5):36-8. [PubMed: 17900040]

27. Kreitzer MJ, Gross CR, Ye X, et al. Longitudinal impact of mindfulness meditation on illness burden in solid-organ transplant recipients. Prog Transplant 2005;15(2):166-72. [PubMed: 16013466]

28. Sullivan MJ, Wood L, Terry J, et al. The Support, Education, and Research in Chronic Heart Failure Study (SEARCH): a mindfulness-based psychoeducational intervention improves depression and clinical symptoms in patients with chronic heart failure. Am Heart J 2009;157(1): 84-90. [PubMed: 19081401]

29. Bohlmeijer E, Prenger R, Taal E, et al. The effects of mindfulness-based stress reduction therapy on mental health of adults with a chronic medical disease: a meta-analysis. J Psychosom Res 2010;68(6):539-44. [PubMed: 20488270]

30. Matousek RH, Dobkin PL, Pruessner J. Cortisol as a marker for improvement in mindfulnessbased stress reduction. Complement Ther Clin Pract 2010;16(1):13-9. [PubMed: 20129404]

31. Chiesa A, Serretti A. A systematic review of neurobiological and clinical features of mindfulness meditations. Psychol Med 2010;40(8):1239-52. [PubMed: 19941676]

32. Carmody J, Baer RA, Lykins ELB, et al. An empirical study of the mechanisms of mindfulness in a mindfulness-based stress reduction program. J Clin Psychol 2009;65(6):613-26. [PubMed: 19267330]

33. Baer RA, Smith GT, Hopkins J, et al. Using self-report assessment methods to explore facets of mindfulness. Assessment 2006;13(1):27-45. [PubMed: 16443717] 
34. Carmody J, Baer RA. Relationships between mindfulness practice and levels of mindfulness, medical and psychological symptoms and well-being in a mindfulness-based stress reduction program. J Behav Med 2008;31(1):23-33. [PubMed: 17899351]

35. Baer RA, Smith GT, Lykins E, et al. Construct validity of the five facet mindfulness questionnaire in meditating and nonmeditating samples. Assessment 2008;15(3):329-42. [PubMed: 18310597]

36. Jha AP, Krompinger J, Baime MJ. Mindfulness training modifies subsystems of attention. Cogn Affect Behav Neurosci 2007;7(2):109-19. [PubMed: 17672382]

37. Tang YY, Ma Y, Wang J, et al. Short-term meditation training improves attention and selfregulation. Proc Natl Acad Sci U S A 2007;104(43):17152-6. [PubMed: 17940025]

38. Sanders WA, Lam DH. Ruminative and mindful self-focused processing modes and their impact on problem solving in dysphoric individuals. Behav Res Ther 2010;48(8):747-53. [PubMed: 20494334]

39. Watkins E, Teasdale JD. Adaptive and maladaptive self-focus in depression. J Affect Disord 2004;82(1):1-8. [PubMed: 15465571]

40. Linehan, MM. Skills Training Manual for Treating Borderline Personality Disorder. Guilford Press; New York, NY US: 1993.

41. Moore A, Malinowski P. Meditation, mindfulness and cognitive flexibility. Conscious Cogn 2009;18(1):176-86. [PubMed: 19181542]

42. Hayes SC, Luoma JB, Bond FW, et al. Acceptance and commitment therapy: model, processes and outcomes. Behav Res Ther 2006;44(1):1-25. [PubMed: 16300724]

43. Baer RA. Self-Focused Attention and Mechanisms of Change in Mindfulness-Based Treatment. Cogn Behav Ther 2009:1. [PubMed: 19697176]

44. Hayes SC. Acceptance and commitment therapy, relational frame theory, and the third wave of behavioral and cognitive therapies. Behavior Therapy 2004;35(4):639-65.

45. Carmody J, Baer RA. How long does a mindfulness-based stress reduction program need to be? A review of class contact hours and effect sizes for psychological distress. J Clin Psychol 2009;65(6):627-38. [PubMed: 19309694]

46. Pradhan EK, Baumgarten M, Langenberg P, et al. Effect of Mindfulness-Based Stress Reduction in rheumatoid arthritis patients. Arthritis Rheum 2007;57(7):1134-42. [PubMed: 17907231]

47. Davidson RJ, Kabat-Zinn J, Schumacher J, et al. Alterations in brain and immune function produced by mindfulness meditation. Psychosom Med 2003;65(4):564-70. [PubMed: 12883106]

48. Gross CR, Kreitzer MJ, Russas V, et al. Mindfulness meditation to reduce symptoms after organ transplant: a pilot study. Adv Mind Body Med 2004;20(2):20-9. [PubMed: 15356953]

49. Rosenzweig S, Greeson JM, Reibel DK, et al. Mindfulness-based stress reduction for chronic pain conditions: variation in treatment outcomes and role of home meditation practice. J Psychosom Res 2010;68(1):29-36. [PubMed: 20004298]

50. Segal, ZV.; Williams, JM.; Teasdale, JD. Mindfulness-Based Cognitive Therapy for Depression: A New Approach to Preventing Relapse. Guilford Press; New York, NY US: 2002.

51. Teasdale JD, Moore RG, Hayhurst H, et al. Metacognitive awareness and prevention of relapse in depression: Empirical evidence. J Consult Clin Psychol 2002;70(2):275-87. [PubMed: 11952186]

52. Teasdale JD. Cognitive vulnerability to persistent depression. Cognition and Emotion 1988;2(3): 247-74.

53. Persons JB, Miranda J. Cognitive theories of vulnerability to depression: Reconciling negative evidence. Cognitive Therapy and Research 1992;16(4):485-502.

54. Williams, M.; Teasdale, J.; Segal, Z., et al. The Mindful Way through Depression: Freeing Yourself from Chronic Unhappiness. Guilford Press; New York, NY US: 2007.

55. Linehan MM, Armstrong HE, Suarez A, et al. Cognitive-behavioral treatment of chronically parasuicidal borderline patients. Arch Gen Psychiatry 1991;48(12):1060-4. [PubMed: 1845222]

56. Fitzcharles MA, Shir Y. New concepts in rheumatic pain. Rheum Dis Clin North Am 2008;34(2): 267-83. [PubMed: 18638677]

57. Montecucco C, Cavagna L, Caporali R. Pain and rheumatology: An overview of the problem. European Journal of Pain Supplements 2009;3(2):105-9. 
58. Reginster JY, Khaltaev NG. Introduction and WHO perspective on the global burden of musculoskeletal conditions. Rheumatology (Oxford) 2002;41(Supp 1):1-2. [PubMed: 12173275]

59. Fitzcharles MA, Almahrezi A, Shir Y. Pain: understanding and challenges for the rheumatologist. Arthritis Rheum 2005;52(12):3685-92. [PubMed: 16329076]

60. Borenstein D. The role of the rheumatologist in managing pain therapy. Nat Rev Rheumatol 2010;6(4):227-31. [PubMed: 20357792]

61. Integration of behavioral and relaxation approaches into the treatment of chronic pain and insomnia. NIH Technology Assessment Panel on Integration of Behavioral and Relaxation Approaches into the Treatment of Chronic Pain and Insomnia. JAMA 1996;276(4):313-8. [PubMed: 8656544]

62. Wolsko PM, Eisenberg DM, Davis RB, et al. Use of mind-body medical therapies. J Gen Intern Med 2004;19(1):43-50. [PubMed: 14748859]

63. Astin JA, Beckner W, Soeken K, et al. Psychological interventions for rheumatoid arthritis: a metaanalysis of randomized controlled trials. Arthritis Rheum 2002;47(3):291-302. [PubMed: 12115160]

64. Dixon KE, Keefe FJ, Scipio CD, et al. Psychological interventions for arthritis pain management in adults: a meta-analysis. Health Psychol 2007;26(3):241-50. [PubMed: 17500610]

65. McCracken LM. Behavioral constituents of chronic pain acceptance: Results from factor analysis of the Chronic Pain Acceptance Questionnaire. Journal of Back \& Musculoskeletal Rehabilitation $1999 ; 13(2)$

66. Brown CA, Jones AK. Meditation experience predicts less negative appraisal of pain: Electrophysiological evidence for the involvement of anticipatory neural responses. Pain. 2010

67. McCracken LM, Gauntlett-Gilbert J, Vowles KE. The role of mindfulness in a contextual cognitive-behavioral analysis of chronic pain-related suffering and disability. Pain 2007;131(1-2): 63-9. [PubMed: 17257755]

68. Schutze R, Rees C, Preece M, et al. Low mindfulness predicts pain catastrophizing in a fearavoidance model of chronic pain. Pain 2010;148(1):120-7. [PubMed: 19944534]

69. Zautra AJ, Davis MC, Reich JW, et al. Comparison of cognitive behavioral and mindfulness meditation interventions on adaptation to rheumatoid arthritis for patients with and without history of recurrent depression. J Consult Clin Psychol 2008;76(3):408-21. [PubMed: 18540734]

70. Morone NE, Greco CM, Weiner DK. Mindfulness meditation for the treatment of chronic low back pain in older adults: a randomized controlled pilot study. Pain 2008;134(3):310-9. [PubMed: 17544212]

71. Morone NE, Rollman BL, Moore CG, et al. A mind-body program for older adults with chronic low back pain: results of a pilot study. Pain Med 2009;10(8):1395-407. [PubMed: 20021599]

72. Goldenberg DL, Kaplan KH, Nadeau MG, et al. A Controlled Study of a Stress-Reduction, Cognitive-Behavioral Treatment Program in Fibromyalgia. J Musculoskeletal Pain 1994;2(2):5366.

73. Grossman P, Tiefenthaler-Gilmer U, Raysz A, et al. Mindfulness training as an intervention for fibromyalgia: Evidence of postintervention and 3-year follow-up benefits in weil-being. Psychother Psychosom 2007;76(4):226-33. [PubMed: 17570961]

74. Astin JA, Berman BM, Bausell B, et al. The efficacy of mindfulness meditation plus Qigong movement therapy in the treatment of fibromyalgia: a randomized controlled trial. J Rheumatol 2003;30(10):2257-62. [PubMed: 14528526]

75. Coelho HF, Canter PH, Ernst E. Mindfulness-based cognitive therapy: evaluating current evidence and informing future research. J Consult Clin Psychol 2007;75(6):1000-5. [PubMed: 18085916]

76. Godfrin KA, van Heeringen C. The effects of mindfulness-based cognitive therapy on recurrence of depressive episodes, mental health and quality of life: A randomized controlled study. Behav Res Ther 2010;48(8):738-46. [PubMed: 20462570]

77. Williams JM, Alatiq Y, Crane C, et al. Mindfulness-based Cognitive Therapy (MBCT) in bipolar disorder: preliminary evaluation of immediate effects on between-episode functioning. J Affect Disord 2008;107(1-3):275-9. [PubMed: 17884176] 
78. Bohlmeijer E, Prenger R, Taal E, et al. The effects of mindfulness-based stress reduction therapy on mental health of adults with a chronic medical disease: a meta-analysis. J Psychosom Res 2010;68(6):539-44. [PubMed: 20488270]

79. Zautra AJ, Davis MC, Reich JW, et al. Comparison of cognitive behavioral and mindfulness meditation interventions on adaptation to rheumatoid arthritis for patients with and without history of recurrent depression. J Consult Clin Psychol 2008;76(3):408-21. [PubMed: 18540734]

80. Sephton SE, Salmon P, Weissbecker I, et al. Mindfulness meditation alleviates depressive symptoms in women with fibromyalgia: results of a randomized clinical trial. Arthritis Rheum 2007;57(1):77-85. [PubMed: 17266067]

81. Weissbecker I, Salmon P, Studts JL, et al. Mindfulness-based stress reduction and sense of coherence among women with fibromyalgia. Journal of Clinical Psychology in Medical Settings 2002;9(4):297-307.

82. Finucane A, Mercer SW. An exploratory mixed methods study of the acceptability and effectiveness of Mindfulness-Based Cognitive Therapy for patients with active depression and anxiety in primary care. BMC Psychiatry 2006;6:14. [PubMed: 16603060]

83. Eisendrath SJ, Delucchi K, Bitner R, et al. Mindfulness-based cognitive therapy for treatmentresistant depression: a pilot study. Psychother Psychosom 2008;77(5):319-20. [PubMed: 18600038]

84. Glaser R, Kiecolt-Glaser JK. Stress-induced immune dysfunction: implications for health. Nat Rev Immunol 2005;5(3):243-51. [PubMed: 15738954]

85. Carlson LE, Speca M, Faris P, et al. One year pre-post intervention follow-up of psychological, immune, endocrine and blood pressure outcomes of mindfulness-based stress reduction (MBSR) in breast and prostate cancer outpatients. Brain Behav Immun 2007;21(8):1038-49. [PubMed: 17521871]

86. Robinson FP, Mathews HL, Witek-Janusek L. Psycho-endocrine-immune response to mindfulnessbased stress reduction in individuals infected with the human immunodeficiency virus: a quasiexperimental study. J Altern Complement Med 2003;9(5):683-94. [PubMed: 14629846]

87. Witek-Janusek L, Albuquerque K, Chroniak KR, et al. Effect of mindfulness based stress reduction on immune function, quality of life and coping in women newly diagnosed with early stage breast cancer. Brain Behav Immun 2008;22(6):969-81. [PubMed: 18359186]

88. Fang CY, Reibel DK, Longacre ML, et al. Enhanced Psychosocial Well-Being Following Participation in a Mindfulness-Based Stress Reduction Program Is Associated with Increased Natural Killer Cell Activity. J Altern Complement Med. 2010

89. Ospina MB, Bond K, Karkhaneh M, et al. Meditation practices for health: state of the research. Evid Rep Technol Assess (Full Rep) 2007;(155):1-263. (155). [PubMed: 17764203] 